\title{
Lusioersily
}

\section{Help-Seeking Beliefs Among Anabolic Androgenic Steroid Users Experiencing Side Effects: An Interpretive Phenomenological Analysis}

Gilmore, H., Shannon, S., Leavey, G., Dempster, M., Gallagher, S., \& Breslin, G. (Accepted/ln press). HelpSeeking Beliefs Among Anabolic Androgenic Steroid Users Experiencing Side Effects: An Interpretive Phenomenological Analysis. Journal of Clinical Sport Psychology.

Link to publication record in Ulster University Research Portal

Published in:

Journal of Clinical Sport Psychology

Publication Status:

Accepted/In press: 04/10/2019

\section{Document Version}

Author Accepted version

\section{General rights}

Copyright for the publications made accessible via Ulster University's Research Portal is retained by the author(s) and / or other copyright owners and it is a condition of accessing these publications that users recognise and abide by the legal requirements associated with these rights.

\section{Take down policy}

The Research Portal is Ulster University's institutional repository that provides access to Ulster's research outputs. Every effort has been made to ensure that content in the Research Portal does not infringe any person's rights, or applicable UK laws. If you discover content in the Research Portal that you believe breaches copyright or violates any law, please contact pure-support@ulster.ac.uk. 
Title: Help-Seeking Beliefs Among Anabolic Androgenic Steroid Users Experiencing Side Effects: An Interpretive Phenomenological Analysis.

\section{Abstract:}

Recreational athletes comprise the most prevalent population using illegal Anabolic Androgenic Steroids (AAS) (Pope et al., 2014). Despite regulatory efforts, substances are widely accessible, and most users report the experience of harmful side effects. It remains unclear why few users seek professional medical help. The aim of this study was to determine AAS users experience of side effects and help-seeking beliefs using an Interpretative Phenomenological Analysis of six interviews. Participants were from the United Kingdom $(\mathrm{n}=5)$ and United States $(\mathrm{n}=1)$, had all experienced side-effects, with some reporting prolonged use of AAS (>10 years), and self-manufacturing the drugs from raw ingredients. Results showed that AAS users discredit medical professionals' competencies, and practice cognitive dissonance by avoiding challenging situations. A microculture for informationsharing has developed among AAS users who initially self-treat to counteract side effects, leaving them vulnerable to further harm. To conclude, there is an urgent need for educational interventions that outline the risky practice of unregulated AAS use and self-treatments, and the need to seek professional help. Such interventions could be developed through a coproduction basis, and be implemented by current/former AAS users alongside the medical community.

Keywords: Cognitive beliefs; Harm minimisation; Cognitive dissonance; Optimism bias; Gym clients; athletes 


\section{Title: Help-Seeking Beliefs Among Anabolic Androgenic Steroid Users Experiencing Side Effects: An Interpretive Phenomenological Analysis.}

Anabolic Androgenic Steroids (AAS) are hormones that comprise derivates of testosterone that regulate the development of male sexual characteristics (Aljubori, 2019). A substance can be defined as an AAS through the following criteria: (i) a chemical, or (ii) pharmacological compound that is related to testosterone, and (iii) not an estrogen, progestin, or a cortisol-based steroid (Goldman, Pope \& Bhasin, 2018). The anabolic effects of AAS on physiological and psychological characteristics include abnormal fat and carbohydrate metabolism, increases in aggression and attention, and enhanced blood flow and up-regulated muscle protein synthesis ( $\mathrm{Yu}, 2014)$. As such, AAS are efficacious in increasing muscular size, performance and aesthetics, and consequently, are prevalent in elite sport and professional bodybuilding (i.e., collective estimate of $13.4 \%$; Sagoe et al. 2014). Surprising to most however recreational sportspeople (e.g., non-elite athletes, fitness clients) report the highest prevalence of illegal AAS usage at $18.4 \%$ (Petrocelli, Oberweis \& Petrocelli, 2008). Therefore, research into this sensitive area has importance for public health providers (Pope et al., 2014).

Given their anabolic functions, most countries permit medical prescription and clinical use of AAS for health conditions (e.g., severe sarcopenia), and therefore permit legal possession (Advisory Council on the Misuse of Drugs, 2010). An unintended consequence of this public health strategy has been the increasing public demand for AAS. Further, despite prohibition of AAS in commercial markets, underground sources (e.g., internet) facilitated an increased usage among the general population (Goldman, Pope \& Bhasin, 2018). Indeed, a metaanalyses by Sagoe et al. (2014) noted a lifetime prevalence rate of $3.3 \%$, with $6.4 \%$ in males and $1.6 \%$ in females, with the conclusion that AAS use is a widespread public health concern. 
Researchers have established that many recreational athletes consume AAS for mostly cosmetic and personal image motives (e.g., improve lean body mass, reduce fat) and many AAS users conduct their own risk-benefit analyses, to the extent that the cosmetic benefits of AAS appear to outweigh the negative health risks (Kanayama and Pope, 2018). In contrast to recreational drugs (e.g., narcotics) typically encountered during adolescence, AAS is a lateonset form of substance misuse (i.e., median=22 years of age) (Karazsia, Crowther \& Galioto, 2013). Moreover, Pope et al. (2014) have argued that many AAS users may go undetected, largely because the side effects associated with AAS are considered negligible by many users.

When self-administered without formal medical guidance, the use of AAS, especially from blackmarked sources, poses various physical and psychological risks (Perry and Hughes, 1992; Iriarte and Andrade, 2002; Baggish et al, 2010). Existing regulatory efforts have failed to protect consumers by not accounting for the health threats posed by AAS (Goldman, Pope \& Bhasin, 2018). Indeed, Aljubori (2019) outlined various physiological side effects ranging from heart hypertrophy to kidney failure, and deepened voice in women, and hypogonadism (i.e., reduced testosterone production) in men. Further evidence (Karazsia, Crowther \& Galioto, 2013) suggests that mental health issues (e.g., depression, eating disorders) are associated with AAS use (Sagoe, Adreassen \& Pallesen, 2014). It has also been found that AAS users often self-medicate with doses that far exceed medical norms (i.e., from 1000 up to $5000 \mathrm{mg}$ per-week), and engage in high-risk behaviours such as needle sharing (Goldman, Pope \& Bhasin, 2018). Alarmingly, even when individuals are aware of information pertaining potential health harms of AAS, they often persist with their use (Walker \& Joubert, 2011; AlFalasi et al., 2008). To reduce engagement with such potentially harmful AAS use 
and their associated risks, it is necessary to understand the factors underpinning professional help-seeking behaviours among AAS users.

The number of AAS users registered with advice services in the UK has increased in recent years, but the majority of users remain reluctant to engage with the available support (Evans, Brown and McVeigh, 2009; Interagency Drug Misuse Database, 2009). For instance, although recreational AAS users are registered with a General Practitioner (GP) as a first point of medical contact, GPs report a lack of help-seeking from AAS users (Lenehan, 2003). Grogan et al. (2006) reported that competitive bodybuilders may not seek help because of a lack of confidence in health professionals competencies, however this issue has yet to be explored with recreational athletes. Further, there remains a paucity of information on why most users do not seek help when they experience unwanted side effects, and what information and/or treatment strategies they use to self-manage (Yu, Hildebrandt \& Lanzieri, 2015). Indeed, the widespread availability of black market 'stacks,' that include unregulated substances to self-treat and counteract side-effects, presents further risk to the public (Goldman, Pope \& Bhasin, 2018). Hence, there is a need for a research-informed understanding of the psychosocial factors that underpin professional help-seeking beliefs among AAS users (Grogan et al., 2006; Yu, Hildebrandt \& Lanzieri, 2015).

Given the lack of readily available interventions for populations implementing stigmatised practices in sport and exercise contexts (Breslin, Shannon, Haughey, Donnelly \& Leavey, 2017; McGuane, Shannon, Sharpe, Dempster \& Breslin, 2019), Tamminen and Bennett (2017) advocate as an important initial step, the development of rich information through qualitative methodologies. In particular, Interpretative Phenomenological Analysis (IPA) is method that entails purposively selecting individuals, and providing participants with an opportunity to describe their unique subjective experience of personal and social phenomena 4 
in relation to the topic studied (Smith \& Osbourne, 2003; Smith, 2004). Unlike other qualitative methodologies, IPA adopts a person-by-person, idiographic focus, and permits detailed insights on a topic that have not yet been explored (Larkin \& Thompson, 2012). Given help-seeking is typically a unique and private experience, IPA can add value to understanding how social, cultural and psychological processes influence AAS use, and subsequent help-seeking behaviours.

Therefore, the aim of the current study was to explore AAS use among recreational athletes and/or fitness clients, and specifically delve into the area of professional help-seeking for side effects. We sought to explore three key areas: (i) Users' beliefs regarding the safety of AAS, and the information shared among peers; (ii) the treatments utilised and decisionmaking processes involved in seeking professional help (or not); and (iii) possible routes to healthcare provision.

\section{Method}

\section{Participants and Procedure}

The research was approved by Ulster University Research Ethics Filter Committee. We recruited participants through the Internet and by snowball sampling wherein participants recruited other hard to reach participants. Given the lower prevalence of, and difficulty in recruiting female AAS users outside of the bodybuilding subculture (Kimergard, 2015; Sagoe et al., 2014), only male users were approached for inclusion. Six males from the United Kingdom ( $\mathrm{n}=5)$ and United States $(\mathrm{n}=1)$ agreed to participate (out of 7 approached), which adhered to the idiographic focus within Interpretative Phenomenological Analysis (IPA; Smith \& Osborn, 2003). As part of our inclusion criteria we specifically sought recreational fitness clients and non-elite athletes who had experienced side-effects. 
Following ethical approval the primary investigator (PI) met the participants and outlined the study, highlighting that all responses would be anonymous. Under the guidance of two co-investigators with comprehensive experience in using IPA and qualitative methodologies, the PI collected data through semi-structured face-to-face interviews with each participant, at a convenient time and location.

A semi-structured interview guide covering three broad areas was devised to ensure that a systematic line of inquiry was followed with each participant: (i) the experience and beliefs of using AAS, and side-effects experienced (ii) treatments for side effects and continuing/stopping using AAS; (iii) the experience of help-seeking. However, the interviews also ensured flexibility through allowing participants to spontaneously raise issues important to them (Smith \& Osborn, 2003). Adhering to an IPA approach (Pietkiewicz \& Smith, 2012), the PI conducted the interviews through a neutral and facilitative approach, providing participants with opportunities for reflecting on, and making sense of their experiences of AAS use and help-seeking attitudes/behaviours. Individual interviews lasted on average 60 minutes and were transcribed verbatim.

\section{Data Analysis}

Participant's accounts were analysed using IPA (Smith, Flowers and Larkin 2009; Smith and Osbourne, 2003). This method employed an idiographic multiple-case study approach to analysis, described by Smith $(2004$, p. 41) as a process that starts with: (i) "the detailed examination of one case study until some degree of closure or gestalt has been achieved"; (ii) continues with "a detailed analysis of the second case, and so on through the corpus of cases"; and (iii) moves on to "attempt to conduct a cross case analysis." 
The authors (a sport and exercise psychologist, a Masters of Science student, a 141 professor in health psychology, two PhDs in health psychology, and a General Practitioner) all had prior experience in using qualitative research methods. The PI transcribed each interview, and individually coded the data using close line-by-line coding to produce themes and subordinate themes (Larkin et al., 2006). To ensure quality and accuracy, the following steps were taken to ensure rigour (Tracy, 2010). First, two authors read and reviewed the PI's coded data. The dependability of the findings was apparent in their agreement regarding the themes and sub-themes identified (Larkin \& Thompson, 2012). Their findings were then formally discussed and debated among the research team, and cross-examined until consensus was reached. Once analyses was complete, extensive participant quotations were included in the text, such that readers have the opportunity to assess detail and develop their own conclusions (Tracy, 2010). Finally, all authors contributed to the writing and review of the article.

\section{Results and Discussion}

All participants were white males aged between 23 and 39 years old, and comprised a range of AAS users including recreational athletes (e.g., rugby) and fitness clients, who held various motives for use (e.g., cosmetic reasons, self-medication for self-diagnosis for low manufacturing the drugs from raw ingredients. Participants had all experienced unwanted side effects. Table 1 below shows their demographic and contextual information. 

psychological side effects (Goldman, Pope \& Bhasin, 2018; Aljubori, 2019). Moreover, users tended not to seek, or consider, professional help when presented with side effects, subsequently practicing personalised forms of risk-benefit analyses (Kanayama \& Pope, 2018), cognitive dissonance, and underground forms of self-treatment (Karazsia, Crowther, \& Galioto, 2013). Whilst acknowledging that the present study comprised a small number of participants, and therefore findings are not widely generalisable, the results highlight an important need for, and important considerations in the development of educational interventions for recreational athletes and fitness individuals. Following the idiographic approach to analyses, comparisons between the participants resulted in four master themes developed from the data (i.e., a belief that GP's and medical staff are ineffective; biasing harms and benefits; a subculture in facilitating and sharing information; maladaptive harm minimisation). Each master theme encompassed sub-themes that provided additional detail and insights into the participants individual and collective experiences. An overview of the findings are provided in Table 2, and a detailed summary and cross-comparison with extant literature is provided below.

*** Insert Table 2 here ***

\section{Master Theme 1: A belief that GPs and medical staff are ineffective}

Various assumptions about statutory health services and GPs embodied both a distrust and lack of confidence in their competencies regarding AAS. It was evident that there was a presupposition that presenting to a GP or medical professional will lead to the participant being challenged to reconsider their use of AAS for legal and health reasons. 
For instance, only P4 in the study fully disclosed their use to a medical professional, and this was not to their GP, and also not to the first Endocrinologist to whom he was referred to. Healthcare effectiveness hinges on trust and cooperation between patient and consultant (Mansfield, Addis, \& Mahalik, 2003), and the perceptions of inadequate healthcare provision and legal stipulations, may therefore hinder levels of professional help-seeking. Such sentiments have also been expressed by professional bodybuilders (Grogan et al., 2006), and elite athletes (Kanayama \& Pope, 2018), and this is one of the first studies to establish such beliefs among recreational athletes.

Specifically, participants emphasised the perceived inferior medical knowledge of health professionals in comparison to themselves, or that of their peers. For example, two participants outlined the following negative views of healthcare professionals:

P2: “They have no...idea what's going on, their level of knowledge is laughably poor... (with reference to endocrinologists), most will not actually acknowledge the role of estrogen in the male body."

P4: "Doctors are pretty ignorant when it comes to it... I spent the last year dealing with urologists and endocrinologists who are idiots. I knew the guy was wrong, so I asked for a second opinion. The thing is, any time I've spoken to endocrinologists they have referred to a book. I know they can't know everything, but if you have been referred to a specialist you want to know the person dealing with you is not just picking up some book that any old mong can pick up in a library. I've read those, I know all that stuff, I want someone who has practical knowledge of cases like these, and the nuances each individual has." 
A further subtheme (unwillingness to disclose to the doctor; see Table 2) indicated that participants avoided any formal discussion of the side effects experienced with GPs. By generalising negative views of professional medical staffs' knowledge regarding treatments, the participants could be viewed as practising cognitive dissonance. Cognitive dissonance is defined as altering one's beliefs and behaviours to reduce the discomfort associated with conflicting or opposing information regarding one's behaviours (Festinger, 1957). Authors (Newby-Clark, McGregor, \& Zanna, 2002) have suggested a link between cognitive dissonance and negative emotions. In respect of our participants, cognitive dissonance may explain why they choose not to disclose to their AAS usage to GPs (e.g., P1 and P4). The findings expressed are reflective of attitudes held by competitive bodybuilders (Lenehan, 2003; Karazsia, Crowther, \& Galioto, 2013), such that, holding a prejudiced negative view of formal medical support means that seeking professional help is not an appropriate response.

Inherent within the cognitive dissonance practiced, many of the participants also expressed an optimism bias regarding their ability to self-manage and consequently mitigate the unwanted side effects without the help of a GP. Within Optimism Theory (Shepperd, Patrick, Jodi, and Meredith, 2002), optimism bias refers to when people view their situation in a positive light and believe they are less likely than others to experience negative effects, and is mediated by increased perceptions of self-control (Shepperd, Patrick, Jodi, and Meredith, 2002). In this context, through experiencing personal agency through seeking underground support (e.g., reading web discussion boards, speaking to peers), and then believing that they are more educated than formal medical staff, may have facilitated an optimism bias, and therefore further low levels of professional help-seeking (van Harreveld, van der Pligt, \& Yael, 2009). 

also facilitated a greater risk of underground forms of treatment, leaving users vulnerable to further harm (e.g., users reported taking 'stacks' of substances to counteract side effects) (Goldman, Pope \& Bhasin, 2018). From a personality-focused perspective, the sentiments expressed by all but one of the participants (P6) regarding their superior knowledge of AAS may also suggest a degree of narcissism among recreational appearance-focused athletes, as is the case in professional bodybuilders (Pawłowska, Zaręba, \& Potembska, 2016). Conversely, P6, who experienced a single negative side effect (i.e., heightened aggression), avoided further use of the substances and admitted being poorly educated, and described how he followed his coach's advice to use AAS because of his self-confessed inadequacies.

All participants held the view that disclosure to a GP or medical professional would be met by a verbal reprimand and/or that the GP would patronise or sneer at the patient in this scenario. The colloquialism of "looking down their nose at you" was used explicitly by P1 and P2, suggesting an anticipated moralising aspect of the clinical encounter. In this view, when GP inquired about their use of drugs, participants felt a prejudiced form of stigma. These findings align with extant research (Yu, Hildebrandt \& Lanzieri, 2015) indicating a prejudiced view of AAS users among healthcare providers, when in comparison to their views of other drug users. Indeed, to improve such engagement between the communities, Anawalt (2019) among others (Creado \& Reardon, 2019) have emphasised a compassionate, and patient-centred approach from practitioners, such that self-efficacy is encouraged during 252 periods of resistance. 
The side effects reported among our participants support studies (Parkinson \& Evans, 2006), indicating that the vast majority $(99.2 \%)$ of users report harmful side effects from AAS use. In this regard, the second master theme highlighted confirmation bias on the effects of AAS use. Confirmation bias permits a selective attention paid to information which supports a person's beliefs, and the subsequent overlooking of information which challenges a person's beliefs (Lord, Ross, Lepper, 1979). The confirmation bias expressed by our participants was evident in their belief that AAS use was safe, and allowed them to achieve personal goals. For instance, P2 stated that AAS helped him gain education, and encouraged him to maintain an active, healthy lifestyle, whilst also listing sixteen adverse side effects experienced through AAS use. This 'bracketing off' for serious risk factors ensured that confirmation bias is used as a strategy to prevent the discomfort of dissonance (van Harreveld, van der Pligt, and de Liver, 2009). Thus, confirmation bias differs from feelings of ambivalence, in that ambivalence is holding conflicting attitudes towards a subject (Cooper, 2007).

In another example of 'bracketing off' potential harms, P2 noted that he suffered from cysts to his liver, yet also mocked the notion of steroids causing liver cancer. Likewise, P3 stated that they experienced few serious issues, and confirmation bias appears evident in his self-diagnosis and self-treatment, as indicated below.

\section{P3: "As far as serious issues go I've never really heard of any serious issues and} it's not like it's something you can overdose on. Unless you get an infection and you leave it too long and it goes septic, you are not going to die...There was about a three week period where I was lactating, but that cleared up as soon as I handled the side effect. Everything I have encountered can pretty much be avoided if you know how to handle it." 
Because participants displayed a sense of control and personal knowledge of AAS, participants displayed confirmation bias regarding their self-categorisation as a sensible ' $d r u g$ user', rather than an 'drug abuser'. For instance, P2 made the distinction that, while the medical community would stigmatise him an abuser, he would consider himself a responsible user. This perspective is supported in one of the few qualitative studies among recreational athletes (Kimergard, 2015), in which users tend to ignore the potential harms of risky behaviours, and rather, convey their control and strategic risk management. Lastly, all participants expressed a degree of scorn towards uneducated users whom they deemed irresponsible. As such, there appears to be converging evidence that recreational users tend to minimise, or ignore problems and emphasise their ability to cope (Monaghan, 2001; Petrocelli, Oberweis \& Petrocelli, 2008; Kimergard, 2015). A biased rationalisation process allows individuals to pursue muscular performance and appearance goals.

\section{Master Theme 3: A subculture in facilitating and sharing information}

The participants consistently reported a sense of belonginess to a microculture which transfers knowledge about AAS usage, and sustains beliefs and norms. The presence of such dynamic social processes also aligns with components of Social Identity Theory (SIT; Tajfel, 1982), to the extent that individuals practice 'in group' hidden attitudes, norms and behaviours, that 'out groups' are not privy to. Indeed, studies (Dunn, Mazanov \& Sitharthan, 2009) have indicated that being acquainted, or friendly with other AAS users significantly 
foundation for their information, and motives to pursue usage of steroids. A common rationalisation for this view, specifically articulated within the documentary 'Bigger, Faster, Stronger', is that AAS are not as harmful as other more common substances such as alcohol and tobacco. Indeed, and through a confident demeanour, P1, P2, P5 and P6 all outlined that AAS can be used safely and has many positive medical benefits, with P1 specifically stating that AAS is not in the top 100 of reasons patients are admitted to emergency rooms, whilst alcohol and tobacco rank higher (n.b. the documentary used unadjusted statistics for population usage of AAS).

An additional sentiment displayed by the participants was that they belonged to a subculture that held 'insider' knowledge with regard to accessing AAS, dosages, correct formulation of 'stacks' of substances, and being privy to information that is exclusive to the culture. Our findings therefore support extant evidence among recreational athletes (Petrocelli, Oberweis \& Petrocelli, 2008; Kimergard, 2015), indicating a dissemination of private knowledge among experienced and inexperienced users. Further, all our participants cited the internet as a pertinent source of information, and as an accessible way to 'underground' markets. and cited the benefit that these internet forums ensure anonymity and allow for people to ask questions and receive answers on the use of AAS. Research (Cordaro, Lombardo \& Cosentino, 2011) has indicated that unregulated internet sources often recommended doses that are two-fourfold higher than current medical norms, and further work (Clement et al., 2012) has proposed that less than $5 \%$ of websites provided accurate health information regarding steroids. Such misinformation among forums and product websites, may have provided our participants with greater perceived knowledge, and therefore a greater risk of 14 
engaging with maladaptive help-seeking behaviours because of optimism and confirmation bias.

\section{Master Theme 4: Maladaptive harm minimisation}

327 The final theme relates to 'harm minimisation', which occurred as a maladaptive form of self-treatment and help-seeking. The most pertinent finding of this study is that almost all (5/6) participants attempted to self-treat with other substances following their self-diagnosis of side effects. This maladaptive response to harm minimisation ties further with the control aspect of optimism bias, such that self-diagnosing and self-treating is a further controlseeking behaviour (Shepperd, Patrick, Jodi, \& Meredith, 2002). These behaviours demonstrate cause for concern, as the self-treatment of symptoms without medical formal supervision from a medical professional is a risky practice (Cordaro, Lombardo \& Cosentino, 2011; Clement et al., 2012). Furthermore, a polypharmacy of AAS use with other illicit substances has been found to induce harmful psychophysical effects (Sagoe et al., 2015). with substances and methods found illegally on the 'black market'. Substances ranged from the use of tamoxifen to combat gynaecomastia, to the act of bloodletting through a peristaltic pump to relieve symptoms of high blood pressure and polycythaemia (P2). Critically, at the first sign of trouble, the usual response is self-treat and, failing that, to find someone in the social network to 'fix' them, as stated by P6. The following statement by P4 further outlines the maladaptive cycle of information sharing, and underground forms of self-treatment among AAS users, which ultimately exposes them to further potential harm; 
In contrast to a qualitative study among recreational AAS users in the UK (Kimergard, 2015) none of our participants reported contact with formal harm reduction services. From an intervention production standpoint, existing health harm reduction services have been largely top-down focused (i.e., expert led) rather than consumer-led (Filipe, Renedo \& Marston, 2017). Importantly, the lack of stakeholder involvement into such interventions can often result in a perceived lack of trust and confidence among potential participants, and thus lack of subsequent engagement, which may have been the case for some of our participants.

Non-AAS drugs such as fat burners, and 'stacks' that included multiple unregulated substances to counteract side effects, were also consumed by the participants. Our findings thus corroborate a meta-synthesis of existing studies (Sagoe et al., 2015) that highlighted an association of AAS use with other illicit drugs. Several participants also indicated the usage of recreational drugs (e.g., P3), who indicated that while AAS may be viewed as: being aware of aggression and irritation during his AAS use, and indicated seeking a greater ability to be calmer by reducing and stopping AAS use. P2 also reported that when he used trenbolone he informed his partner of mood changes, perceived by him as minimising the potential damage to social connections.

\section{Clinical implications}

367 The aims of this study were to understand AAS users' help-seeking beliefs from medical professionals, and their experience of, support sought, and treatments used for AAS-induced side effects. Findings support recent evidence that AAS use is a widespread public health 
issue (Sagoe et al., 2014), and existing regulatory efforts have failed to account for the health threats posed by AAS (Goldman, Pope \& Bhasin, 2018), demonstrating a clear need for interventions among the present population. Given the small sample size, findings should be interpreted with caution. However, the flexible IPA approach (Smith \& Osborn, 2003) yielded valuable and detailed insights which unearthed various novel findings regarding AAS users' beliefs, and may translate into policy, research and clinical practice.

Specifically, our findings showed that AAS users who experience side effects are likely to self-diagnose and self-treat, because: (i) they believe that GPs and professional medical staff are ineffective and lack knowledge of AAS; (ii) users' bias harms and benefits of AAS, and practice cognitive dissonance by avoiding situations in which their views can be challenged; (iii) a subculture facilitates and shapes an ill-informed discourse that AAS side-effects can be safely self-treated, and; (iv) unregulated pharmacological forms of self-treatment (e.g., stacks) are widely accessible through the black market, which are often advocated for by experienced users. Subthemes revealed that the perceived inferior knowledge of the formal medical community is reinforced by pro-steroid information sources (e.g., internet, peers), and builds a greater perceived sense of self-control in line with the theory of optimism bias. This pathway to increased control is further facilitated through the practicing of cognitive dissonance and confirmation bias. These master and sub-themes are interlinked, and all present challenges for the medical profession to overcome.

In order to curb the increasing rates of harmful and unregulated AAS use, further on-going government funding and support should be given towards nationwide prevention schemes and AAS awareness training (Evans, Brown \& McVeigh, 2009). In this vein, free and confidential screening, and help-seeking advice could be made available through fitness centres, sports clubs, health centres and online mediums (Reardon \& Factor, 2010). It is 17 
recommended that focus be given towards treatment and prevention strategies in order to disrupt the established negative cycle of AAS initiation and subsequent dependence, withdrawal and relapse (Goldman, Pope, \& Bhasin, 2018). Such services could be founded on the optimistic view that most reported side-effects are treatable, and often reversable through existing formal medical care (Anawalt, 2019).

Our study, among others (Karazsia, Crowther, \& Galioto, 2013), highlighted that the interactions between medical professionals and clients will be crucial to effective delivery of such programmes, to the extent that prejudice to one another is common among both medical professionals AAS users (Yu, Hildebrandt \& Lanzieri, 2015). Therefore, from a healthcare systems perspective, we recommend practitioners and clinical health providers adopt a clientcentred approach during counselling, education and communication of awareness messages (Crawford, Brown, Kvangarsnes, \& Gilbert, 2014). Such approaches can support clients' needs through active listening, provision of opportunities for client input, regular positive and constructive feedback, and consistent encouragement for patients to take an active role in the care they are receiving alongside the healthcare providers (Ryan \& Deci, 2017).

Client-centred care has been shown to be more effective when interventions are designed and implemented through a co-production basis that integrates all of the relevant stakeholders from the outset (e.g., patients, counsellors, recruitment officers, policy makers) (Palumbo, 2016). Co-production efforts could invite current and/or past AAS users to design and implement programmes alongside formal medical providers. Such interventions could also include case studies on the misinformation conveyed by unregulated black-marketed sources, in addition to harmful side-effects and routes to non-stigmatising healthcare (Palumbo, 2016). It is proposed that over time such efforts may lead to consumer-driven prevention efforts, which can be seen in other domains (e.g., smoking; Hawkins et al., 2017). However, it is 18 
418

important to state that given evidence-based harm reduction and treatment programmes remain to be developed for the recreational athlete population, ongoing and cautious effort should be spent during programme development and refinement, in order to ensure feasibility and acceptability (Breslin et al., 2017; Oliver, Kothari \& Mays, 2019).

Lastly, it is evident that research on specific harm reduction services and psychiatric approaches to treatment is lacking among athletes (Creado, \& Reardon, 2016). Hence, coproduction interventions should involve regular and reflective research practice, wherein all stakeholders agree on the research questions, collection and interpretation of data, and recommendations on further therapeutic approaches (Oliver, Kothari \& Mays, 2019). We hope that that the present study contributes further insight into the experiences of AAS use among recreational athletes, and ultimately contributes to harm reduction of AAS and associated behaviours.

\section{Funding details}

No funding was sought or used during the process of this study.

\section{Disclosure statement}

All authors declare that we have no conflict of interest to report.

\section{References}

Advisory Council on the Misuse of Drugs. (2010, September). Consideration of the anabolic steroids. Report published by Advisory Council on the Misuse of Drugs, London. 
Help-Seeking Beliefs Among AAS Users

438

439

440

441

442

443

444

445

446

447

448

449

450

451

452

453

454

455

456

457

458

Aljuboury, N. H. (2019). Misuses and side effects of steroids derivatives. International Journal of Medical Sciences, 2(1), 1-4.

Al-Falasi, O., Al-Dahmani, K., Al-Eisaei, K., Al-Ameri, S., Al-Maskari, F., Nagelkerke, N., \& Schneider, J. (2008). Knowledge, attitude and practice of anabolic steroids use among gym users in Al-Ain District, United Arab Emirates. Open Sports Med J, 2, 75-81.

Anawalt, B. D. (2019). Diagnosis and management of anabolic androgenic steroid use. The Journal of Clinical Endocrinology \& Metabolism.

Baggish, A. L., Weiner, R. B., Kanayama, G., Hudson, J. I., Picard, M. H., Hutter, A. M., \& Pope, H. G. (2010). Long-term anabolic-androgenic steroid use is associated with left ventricular dysfunction. Circulation: Heart Failure, 3(4), 472-476.doi: 10.1161/

Bell, C. (Director). (2008). Bigger Faster Stronger [Movie].USA: Madman Movies.

Berning, J. M., Adams, K. J., \& Stamford, B. A. (2004). Anabolic steroid usage in athletics: facts, fiction, and public relations. The Journal of Strength \& Conditioning Research, 18(4), 908-917.

Breslin, G., Shannon, S., Haughey, T., Donnelly, P., \& Leavey, G. (2017). A systematic review of interventions to increase awareness of mental health and well-being in athletes, coaches and officials. Systematic reviews, 6(1), 177.

Cooper, J. (2007). Cognitive dissonance: 50 years of a classic theory. Sage.

Cordaro, F. G., Lombardo, S., \& Cosentino, M. (2011). Selling androgenic anabolic steroids by the pound: identification and analysis of popular websites on the Internet. Scandinavian Journal of Medicine \& Science in Sports, 21(6), e247-e259. 
Help-Seeking Beliefs Among AAS Users

459

460

461

462

463

464

465

466

467

468

469

470

471

472

473

474

475

476

477

478

479

480

Clement, C. L., Marlowe, D. B., Patapis, N. S., Festinger, D. S., \& Forman, R. F. (2012). Nonprescription steroids on the Internet. Substance Use \& Misuse, 47(3), 329-341.

Crawford, P., Brown, B., Kvangarsnes, M., \& Gilbert, P. (2014). The design of compassionate care. Journal of Clinical Nursing, 23(23-24), 3589-3599.

Creado, S., \& Reardon, C. (2016). The sports psychiatrist and performance-enhancing drugs. International Review of Psychiatry, 28(6), 564-571.

Dunn, M., Mazanov, J., \& Sitharthan, G. (2009). Predicting future anabolic-androgenic steroid use intentions with current substance use: findings from an Internet-based survey. Clinical Journal of Sport Medicine, 19(3), 222-227.

Evans-Brown, M., and McVeigh, J. (2009). Anabolic steroid use in the general population of the United Kingdom. In V. Møller, P. Dimeo and M. McNamee, (Eds.), Elite sport, doping, and public health (pp 75-97). Odense, Denmark: University of Southern Denmark Press.

Festinger, L. (1962). A theory of cognitive dissonance (Vol. 2). Stanford university press.

Filipe, A., Renedo, A., \& Marston, C. (2017). The co-production of what? Knowledge, values, and social relations in health care. PLoS biology, 15(5), e2001403.

Goldman, A. L., Pope Jr, H. G., \& Bhasin, S. (2018). The Health Threat Posed by the Hidden Epidemic of Anabolic Steroid Use and Body Image Disorders Among Young Men. The Journal of Clinical Endocrinology \& Metabolism, 104(4), 1069-1074.

Grogan, S., Shepherd, S., Evans, R., Wright, S., \& Hunter, G. (2006). Experiences of Anabolic Steroid Use In-depth Interviews with Men and Women Body Builders. Journal of health psychology, 11(6), 845-856. doi: 10.1177/1359105306069080 
Help-Seeking Beliefs Among AAS Users

481

482

483

484

485

486

487

488

489

490

491

492

493

494

495

496

497

498

499

500

501

502

503

504

Gupta, L., \& Towler, B. (1997). General practitioners' views and knowledge about anabolic steroid use-survey of GPs in a high prevalence area. Drug and alcohol review, 16(4), 373379. DOI: http://dx.doi.org/10.1080/09595239700186761

Harris, P. (1996). Sufficient grounds for optimism?: The relationship between perceived controllability and optimistic bias. Journal of Social and Clinical Psychology, 15(1), 9-52. doi: $10.1521 /$ jscp.1996.15.1.9

Hawkins, J., Madden, K., Fletcher, A., Midgley, L., Grant, A., Cox, G. \& White, J. (2017). Development of a framework for the co-production and prototyping of public health interventions. BMC public health, 17(1), 689.

Home Office. (2010). Drug misuse declared: findings from the 2009/10 British Crime Survey. (Home Office Statistical Bulletin 13/10). London: Hoare, J. and Moon, D. (Eds.). Retrieved from http: //webarchive.nationalarchives.gov.uk/+/http: //www.homeoffice.gov.uk/publications/science-research-statistics/researchstatistics/drugs-alcohol-research/hosb1310/.

Iriarte, J. A. B., and Andrade, T. M. (2002). Body-building, steroid use, and risk perception among young body-builders from a low-income neighborhood in the city of Salvador, Bahia State, Brazil. Cad. Saúde Pública, Rio de Janeiro, 18(5),1379-1387.

Interagency Drug Misuse Database. (2009). Centre for Public Health, Liverpool. John Moores University

Kanayama, G., \& Pope Jr, H. G. (2018). History and epidemiology of anabolic androgens in athletes and non-athletes. Molecular and cellular endocrinology, 464, 4-13.

Karazsia, B. T., Crowther, J. H., \& Galioto, R. (2013). Undergraduate men's use of performance-and appearance-enhancing substances: An examination of the gateway hypothesis. Psychology of Men \& Masculinity, 14(2), 129. doi: 10.1037/a0027810 
Help-Seeking Beliefs Among AAS Users

505

506

507

508

509

510

511

512

513

514

515

516

517

518

519

520

521

522

523

524

525

526

527

Klein, C. T., \& Helweg-Larsen, M. (2002). Perceived control and the optimistic bias: A metaanalytic review. Psychology and Health, 17(4), 437-446. DOI:10.1080/0887044022000004920

Kimergård, A. (2015). A qualitative study of anabolic steroid use amongst gym users in the United Kingdom: motives, beliefs and experiences. Journal of Substance Use, 20(4), 288294.

Larkin, M., \& Thompson, A. (2012). Interpretative phenomenological analysis. Qualitative research methods in mental health and psychotherapy: A guide for students and practitioners, 99-116.

Lenehan, P. (2003). Anabolic steroids and other performance enhancing drugs. London: Taylor and Francis.

Lindström, M., Nilsson, A. L., Katzman, P. L., Janzon, L., \& DYMLING, J. F. (1990). Use of anabolic-androgenic steroids among body builders-frequency and attitudes. Journal of Internal Medicine, 227(6), 407-411. DOI: 10.1111/j.1365-2796.1990.tb00179.x

Lord, C. G., Ross, L., \& Lepper, M. R. (1979). Biased assimilation and attitude polarization: The effects of prior theories on subsequently considered evidence.Journal of Personality and Social Psychology, 37(11), 2098. doi: 10.1037/0022-3514.37.11.2098

Mansfield, A. K., Addis, M. E., \& Mahalik, J. R. (2003). " Why Won't He Go to the Doctor?": The Psychology of Men's Help Seeking. International Journal of Men's Health, 2(2), 93109. DOI 10.3149/jmh.0202.93

McGuane, T., Shannon, S., Sharp, L. A., Dempster, M., \& Breslin, G. (2018). 'You Wanna Ride Then You Waste': The Psychological Impact of Wasting in National Hunt Jockeys. The Sport Psychologist, 1-27. 
Help-Seeking Beliefs Among AAS Users

McVeigh, J., Beynon, C., \& Bellis, M. A. (2003). New challenges for agency based syringe exchange schemes: analysis of 11 years of data (1991-2001) in Merseyside and Cheshire, United Kingdom. International Journal of Drug Policy,14(5), 399-405. Doi :10.1016/S0955-3959(03)00141-5

Newby-Clark, I. R., McGregor, I., \& Zanna, M. P. (2002). Thinking and caring about cognitive inconsistency: when and for whom does attitudinal ambivalence feel uncomfortable?. Journal of personality and social psychology, 82(2), 157. doi: $10.1037 / 0022-3514.82 .2 .157$

Olrich, T. W. (1999). Perceptions of benefits and losses associated with the use and discontinuance of anabolic-androgenic steroids among male bodybuilders. Journal of Personal \& Interpersonal Loss, 4(3), 231-242. DOI:10.1080/10811449908409732

Oliver, K., Kothari, A., \& Mays, N. (2019). The dark side of coproduction: do the costs outweigh the benefits for health research?. Health Research Policy and Systems, 17(1), 33.

Parkinson, A. B., \& Evans, N. A. (2006). Anabolic androgenic steroids: a survey of 500 users. Medicine and science in sports and exercise, 38(4), 644-651.

Palumbo, R. (2016). Contextualizing co-production of health care: a systematic literature review. International Journal of Public Sector Management, 29(1), 72-90.

Pawłowska, B., Zaręba, Z., \& Potembska, E. (2016). Use of psychoactive substances, body image and characteristics of personality traits in bodybuilders. Current Problems of Psychiatry, 17(1), 9-16.

Petrocelli, M., Oberweis, T., \& Petrocelli, J. (2008). Getting huge, getting ripped: a qualitative exploration of recreational steroid use. Journal of Drug Issues, 38(4), 1187-1205.

Perry, H. and Hughes, G. W. (1992) A case of affective disorder associated with the misuse of 'anabolic steroids'. British Journal of Sport Medicine 26(4), 219-20. 
Help-Seeking Beliefs Among AAS Users

552

553

554

555

556

557

558

559

560

561

562

563

564

565

566

567

568

569

570

571

572

573

Pope Jr, H. G., Kanayama, G., Athey, A., Ryan, E., Hudson, J. I., \& Baggish, A. (2014). The lifetime prevalence of anabolic-androgenic steroid use and dependence in Americans: Current best estimates. The American journal on addictions, 23(4), 371-377.

Pietkiewicz, I., \& Smith, J. A. (2012). Praktyczny przewodnik interpretacyjnej analizy fenomenologicznej w badaniach jakościowych w psychologii. Czasopismo Psychologiczne, 18(2), 361-369.

Reardon, C. L., \& Factor, R. M. (2010). Sport psychiatry: a systematic review of diagnosis and medical treatment of mental illness in athletes. Sports Medicine, 40(11), 961-980. doi:10.2165/11536580-000000000-00000

Ryan, R. M., \& Deci, E. L. (2017). Self-determination theory: Basic psychological needs in motivation, development, and wellness. Guilford Publications, New York.

Sagoe, D., Andreassen, C. S., \& Pallesen, S. (2014). The aetiology and trajectory of anabolicandrogenic steroid use initiation: a systematic review and synthesis of qualitative research. Substance Abuse Treatment, Prevention, and Policy, 9(1), 27.

Sagoe, D., Molde, H., Andreassen, C. S., Torsheim, T., \& Pallesen, S. (2014). The global epidemiology of anabolic-androgenic steroid use: A meta-analysis and meta-regression analysis. Annals of Epidemiology. Doi: 10.1016/j.annepidem.2014.01.009

Sagoe, D., McVeigh, J., Bjørnebekk, A., Essilfie, M. S., Andreassen, C. S., \& Pallesen, S. (2015). Polypharmacy among anabolic-androgenic steroid users: a descriptive metasynthesis. Substance Abuse Treatment, Prevention, and Policy, 10(1), 12.

Shepperd, J. A., Carroll, P., Grace, J., \& Terry, M. (2002). Exploring the causes of comparative optimism. Psychologica Belgica, 42(1/2), 65-98. 
Help-Seeking Beliefs Among AAS Users

574

575

576

577

578

579

580

581

582

583

584

585

586

587

588

589

590

591

592

593

594

595

596

597

Smith, J. A. (2004). Reflecting on the development of interpretative phenomenological analysis and its contribution to qualitative research in psychology. Qualitative research in psychology, 1(1), 39-54. DOI:10.1191/1478088704qp004oa

Smith, J.A., Flowers, P., and Larkin, M. (2009). Interpretative phenomenological analysis: Theory method and research. London: Sage.

Smith, J.A. and Osbourne, M. (2003). Interpretative phenomenological analysis. Qualitative psychology: A practical guide to methods. London: Sage.

Tamminen, K. A., \& Bennett, E. V. (2017). No emotion is an island: An overview of theoretical perspectives and narrative research on emotions in sport and physical activity. Qualitative Research in Sport, Exercise and Health, 9(2), 183-199.

Tracy, S. J. (2010). Qualitative quality: Eight "big-tent" criteria for excellent qualitative research. Qualitative inquiry, 16(10), 837-851.

van Harreveld, F., van der Pligt, J., \& Yael, N. (2009). The agony of ambivalence and ways to resolve it: Introducing the MAID model. Personality and Social Psychology Review, 13(1), 45-61. doi: 10.1177/1088868308324518

Wadler, G. I., and Hainline, B. (1989). Drugs and the athlete. Philadelphia: F.A. Davis.

Walker, D. M., \& Eli Joubert, H. (2011). Attitudes of injecting male anabolic androgenic steroid users to media influence, health messages and gender constructs. Drugs and Alcohol Today, 11(2), 56-70.

Wood, R. I. (2008). Anabolic-androgenic steroid dependence? Insights from animals and humans. Frontiers in neuroendocrinology, 29(4), 490-506. doi:10.1016/j.yfrne.2007.12.002

World Anti- Doping Agency. (2012). The 2012 prohibited list. Retrieved from http://www.wada-ama.org/ 
Help-Seeking Beliefs Among AAS Users

598 Yu, J. G., Bonnerud, P., Eriksson, A., Stål, P. S., Tegner, Y., \& Malm, C. (2014). Effects of 599 Long Term Supplementation of Anabolic Androgen Steroids on Human Skeletal Muscle.

$600 \quad$ PloS one, 9(9), el05330. 